ISSN: 1641-4713; e-ISSN: 2081-1160

DOI: https://doi.org/10.36551/2081-1160.2021.27.229-230

\title{
Miguel Panadero Moya (1939-2021)
}

\author{
Mirosława Czerny \\ Universidad de Varsovia, Polonia
}

Justo antes de Semana Santa recibimos la noticia del fallecimiento de nuestro colega y amigo, el geógrafo español Miguel Panadero Moya, catedrático emérito de la Universidad Castilla-La Mancha.

Conocimos al profesor Miguel Panadero en 1988, en el $46^{\circ}$ Congreso de la ACI en Ámsterdam. España se preparaba para celebrar el $500^{\circ}$ aniversario del Descubrimiento de América, y los geógrafos españoles intensificaban sus investigaciones sobre América Latina. El profesor Miguel Panadero Moya se ofreció a presentar una ponencia sobre los procesos de urbanización en América Latina, dentro del simposio que yo organizaba en el marco del Congreso. Vino en compañía de mi amiga, la ya también fallecida profesora Adela Checa Sánchez de la Universidad Autónoma de Madrid. Adela me lo presentó, diciéndome: Mirka, este geógrafo de Castilla-La Mancha quiere sumarse al trabajo de los geógrafos latinoamericanos europeos. Y así empezó todo. Desde entonces, Miguel nos ha acompañado a congresos y simposios europeos sobre América Latina. Participó activamente en los trabajos del CEISA y en los congresos y simposios sobre América Latina que hemos organizado en Varsovia. Siempre le acompañaba un grupo de entonces jóvenes geógrafos de Castilla-La Mancha: al inicio fueron la doctora Carmen García Martínez y el doctor Francisco Cebrián, los cuales hoy día son profesores de dicha Universidad que continúan el trabajo iniciado por el Prof. Miguel Panadero Moya. Más tarde se sumaron a esta colaboración más geógrafos de dicha Universidad.

Gracias a esta colaboración y a la amistad surgida fruto de ella, en 1996 la Facultad de Geografía y Estudios Regionales de la Universidad de Varsovia y la Facultad de Humanidades de la Universidad Castilla-La Mancha firmaron un 
acuerdo de cooperación académica cuyos resultados han sido permanentes visitas de nuestros estudiantes y profesores a Albacete o a Ciudad Real, correspondidas por los profesores españoles a nuestra Facultad. Ya en el curso académico 1997-1998, las profesoras Maria Skoczek y Bogumila Lisocka-Jaegermann participaron como conferencistas en cursos de doctorado de la Universidad Castilla-La Mancha sobre las transformaciones sociales y económicas en Cuba. El convenio de Erasmus que firmamos es uno de los más antiguos firmados por nuestra Facultad y más fructíferos. Entre 2000 y 2009, el Prof. Miguel Panadero Moya fue el miembro del Comité Editorial de la revista Actas Latinoamericanas de Varsovia. La última vez que nos visitó fue en noviembre de 2008 cuando impartió la conferencia "Recent migration in Spain: socio-demographic and territorial aspects" dentro del proyecto "Challenges for Humanity in the 21st Century" de la Universidad de Varsovia. En la revista Actas Latinoamericanas de Varsovia aparecieron tres artículos de Miguel Panadero Moya: "Urbanización y desarrollo territorial en América Latina en el contexto de la crisis de los años ochenta" (tomo 8, 11-26, 1989); "Los nuevos espacios regionales político-administrativos" (tomo 10, 63-71, 1988); y "Nuevos regiones y regionalismos en América Latina" (tomo 11, 175-191, 1990).

Miguel Panadero Moya ha ostentado diversos cargos políticos y académicos. Entre otros fue Director Provincial de Educación de Albacete, Director General de Universidades de Castilla-La Mancha y Presidente del Consejo Social de la Universidad de Castilla-La Mancha. Fue también Vicepresidente de la Comisión Gestora y Vicerrector de Investigación. También en la UCLM, en 1988 se convirtió en el primer director del Departamento de Geografía y Ordenación del Territorio, y, a su vez, fue creador y primer director del Centro de Estudios Territoriales Iberoamericanos (CETI). Fue Decano de la Facultad de Humanidades de Albacete. En la Asociación de Geografía Española fue Presidente del Grupo de América Latina.

La comunidad académica de la Universidad de Castilla-La Mancha ha perdido a un miembro destacado y nosotros hemos perdido a un amigo que nos acompañó en nuestra senda investigadora en América Latina y en España. 